\title{
A Study of the use of Mobile Application for Train Conductors to Improve Passenger Alarms Management
}

\section{Rail R*}

Purdue University, USA

*Corresponding author: Rajiv Rai, Purdue University, USA, Email: rrai@purdue.edu

\section{Commentary}

Volume 4 Issue 1

Received Date: February 20, 2020

Published Date: February 24, 2020

DOI: $10.23880 /$ eoij-16000227

\section{Commentary}

Multiple occurrences of passenger alarms (for e.g. Call for Aid) during a train journey would cumulatively cause major train delays, which are one of the biggest factors that affect the perceived quality of the train operator. Such unexpected interruptions in the train's schedule could increase the perceived mental workload of the driver by challenging his/ her alarm handling abilities under time pressure. A mobile application (APP) is claimed to provide a complementary alternative for the driver to dispense his/ her responsibilities to the guard for passenger alarm management. This study aims to report the results of A/B testing conducted at a rolling stock manufacturer in United Kingdom. It aims to compare the situational awareness and mental workload of the train crew using a prototype of the APP in a simulated environment. The results of the test shall inform whether the APP can improve the individual performance of the train crew (guard and driver) involved and is therefore a viable solution to reduce the time required for handling passenger alarms. Moreover, the results shall further correlate the effects of the usability of the APP with the individual performance of the user. Finally, the results of the test could make a case for the adoption of modern technological advancements such as the Internet of Things (IoT) in the rail industry to build lasting engagement with its evolving workfare. 